\title{
As crianças ausentes na rua e nas praças Etnografia dos espaços vazios
}

\section{Children absent from streets and squares}

The ethnography of empty spaces

Ileana Wenetz*

\begin{abstract}
Resumo: Neste artigo, busco analisar como os discursos sobre infâncias e brincadeiras são mobilizados na escola e no seu entorno, em ruas e praças do bairro, e de que maneira e com quais efeitos eles atravessam, constituem, modificam, circulam e governam (ou não) os corpos das crianças. O referencial teórico-metodológico que orienta as análises ancora-se nos estudos culturais e o material empírico desta investigação foi constituído através de um trabalho de campo de caráter etnográfico. Procuro apresentar como a cidade não está preparada para as crianças, e como as praças não são o espaço de brincadeiras. Isto foi possível ao observar uma ausência das crianças nesses espaços. Os familiares destacam uma sensação de insegurança e medos para a criança não ficar sozinha brincando na rua.
\end{abstract}

Palavras-chave: Crianças. Espaços vazios. Etnografia. Praças.

Abstract: This paper attempts to analyze how discourses surrounding childhood and games are mobilized in school and in its surroundings, in streets and squares of the neighborhood, and how and by which effects they penetrate, constitute, modify, circulate and govern (or not) the bodies of children. The theoretical and methodological framework that guides the analysis is anchored in cultural studies, and the empirical material of this investigation was gathered during ethnographic fieldwork. We argue that the city is not prepared for children and even the small urban squares do not afford a space for children to play in play, Children are absent from these spaces and their families admit to a sense of insecurity and fear that that prevents the child from playing alone in the street.

Keywords: Children. Empty spaces. Ethnography. Squares.

* Doutora em Ciências do Movimento Humano pela Ufrgs (Porto Alegre, Brasil), pós-doutoranda na Universidade Federal de Santa Catarina em Florianópolis, SC, Brasil; participante do Núcleo de Estudos e Pesquisas Educação e Sociedade Contemporânea <ilewenetz@, gmail.com>.

\begin{tabular}{|c|c|c|c|c|c|}
\hline Civitas & Porto Alegre & v. 13 & n. 2 & p. 346-363 & maio-ago. 2013 \\
\hline
\end{tabular}


Ao aprofundar as reflexões sobre o espaço urbano da cidade e os espaços que as crianças poderiam utilizar, o foco da minha atenção torna-se o bairro, com suas ruas e praças. A circulação ou não das pessoas e a não utilização das ruas servem aqui para compreender os sentidos que os familiares ${ }^{1}$ das crianças outorgam ao próprio espaço onde moram. Dentro dos principais sentidos, os familiares têm preocupações e medos na rua, em relação ao estranho e, principalmente, vivenciam uma sensação de insegurança na cidade. Nesse contexto, exploro quais são as atividades que as crianças realizam, ou no caso desse artigo, aquelas atividades/espaços que eles não realizam/ocupam.

As crianças conformam-se num processo tanto criativo quanto reprodutivo, no qual se daria visibilidade à compreensão de que elas têm capacidade de "formular interpretações da sociedade, dos outros e de si próprios, da natureza, dos pensamentos e dos sentimentos, de o fazerem de modo distinto e de o usarem para lidar com tudo o que as rodeia" (Sarmento, 2005, p. 373). Aqui, não se estaria entendendo as crianças como "objetos manipuláveis, vítimas passivas ou joguetes culturais neutros" (ibid., p. 373), mas como seres capazes de criar e ressignificar sentidos sociais.

Como, então, podemos observar essa vivência coletiva das crianças em outros espaços da cidade? Temos espaços na cidade para as crianças brincarem? Segundo Jane Jacobs (2009, p. 90), vários aspectos podem ser destacados em relação a isso, como

[...] o mito de que os playgrounds e os gramados e os guardas ou supervisores contratados são inerentemente benéficos para as crianças, enquanto as vias públicas, cheias de pessoas comuns, são inerentemente nocivas, revela um profundo desdém pelas pessoas comuns.

A autora destaca que é na convivência com os adultos e nas calçadas que as crianças aprendem características da vida urbana, ou seja, os sujeitos devem assumir, de algum modo, um pouco de responsabilidade pelos outros, mesmo que não se conheçam entre si. Assim, "aprende-se a partir da experiência de outras pessoas sem laços de parentesco ou de amizade íntima ou responsabilidade formal para com você [...]" (ibid., p. 90). É através dos olhares cuidadosos da vizinhança que as pessoas se sentem seguras. Jacobs refere-se, ainda, à "dança da rua" - aquela movimentação rotineira e cotidiana

Ao falar de familiares faço referência principalmente a aquelas pessoas responsáveis pelas crianças. Na maioria dos casos foram mulheres (mães ou avos) que estavam no cuidado delas. Mas também foi identificada a participação ativa de muitos pais. 
que nos é familiar - a qual torna a rua um espaço mais interessante do que os espaços vazios de praças e parques.

Existem controvérsias em relação a esses pontos. É necessário ter parques arrumados, cuidados, limpos e iluminados para as crianças brincarem saudavelmente ou temos esses mesmos parques vazios, onde nenhum adulto 'olha' por elas para protegê-las daquilo que pode ser perigoso no espaço público? Posso confiar nesse espaço público como uma extensão da minha casa e de meu espaço comunitário? As crianças estão mais seguras confinadas em casa sozinhas, na escola ou brincando na rua do bairro?

Nessa direção, procuro problematizar: como se configuram as vivências coletivas das crianças nas suas brincadeiras, em distintos espaços? A partir dessa questão, defino alguns objetivos: identificar como são as relações de sociabilidade das crianças escolarizadas nas suas brincadeiras e mais especificamente, por quais motivos as crianças não estão presentes nos espaços públicos de brincadeiras.

\section{O processo de construção e o contexto da pesquisa}

A partir dos objetivos destacados, decidi realizar um estudo etnográfico que se propôs a pesquisar como se configuravam as vivências coletivas das crianças em diferentes espaços e, mais especificamente, mapear quais estratégias constituem o processo de generificação dessas brincadeiras. ${ }^{2}$

Assim, as escolhas que me levaram a tentar compreender e problematizar os sentidos sociais atribuídos às práticas que conformam/constituem nossa cultura conduziram-me a uma metodologia inspirada nos estudos etnográficos, pois estes permitem responder às questões através do transcorrer do próprio processo investigativo. A finalidade do estudo etnográfico é identificar os significados e as construções presentes nas relações sociais entre os sujeitos que, de certo modo, constituem-nos como indivíduos integrantes de uma determinada sociedade que valoriza alguns traços culturais em detrimento de outros.

A pesquisa de campo teve um ano de duração e teve uma inserção tanto no bairro (em que as crianças moravam) quanto na escola na qual as crianças frequentavam, e esteve em contínua construção, precisando ser modificada durante todo o processo, construindo seis etapas cada uma delas com objetivos e utilização de diversos instrumentos.

$\mathrm{Na}$ etapa um, foram realizadas observações na escola em turmas da primeira à quarta série e um levantamento das crianças (nome, endereço) e localização de suas moradias no mapa. $\mathrm{Na}$ etapa dois, foram realizados e

\footnotetext{
2 Esse aspecto da pesquisa não será explorado neste artigo.
} 
aplicados os questionários, observações no bairro fora do horário escolar, o que teve como resultado uma etnografia dos espaços vazios; realização de entrevistas com sete crianças na escola e a construção e aplicação das fichas nas atividades extras dentro da escola. Na etapa três, foram escolhidas e observadas duas turmas de quarta série. $\mathrm{Na}$ etapa quatro, grupos focais com crianças, com 12 encontros. Na etapa cinco, realizei 38 entrevistas com os pais ou responsáveis pelas crianças, além de entrevistas com alguns professores. $\mathrm{Na}$ etapa seis, foi realizada uma observação no clube de um menino que realizava balé; entrevistas com a criança, com os pais, com os professores e com mães de duas colegas da aula, que também faziam parte da escola.

Neste artigo, darei especial atenção à etnografia dos espaços vazios, pois considero tal reflexão como fundamental no fazer etnográfico. Durante a etapa dois, apesar do tempo de observação de campo, dos deslocamentos pelo bairro ${ }^{3}$ e do mapeamento das praças - ações realizadas em diferentes períodos do ano -, as crianças não estavam na rua. Vários ensaios dos motivos dessa ausência poderiam ser elencados: frio, chuva, ${ }^{4}$ praças mal cuidadas e/ou escuridão no inverno; viagens familiares em períodos de férias; preferências dos familiares por manter as crianças dentro de casa; algum outro espaço que eu não conhecesse etc. Assim, embora os dados identificados em etapas anteriores 5 indicassem que as famílias e suas crianças usufruíam das praças, as crianças não se encontravam lá. Desse modo, as peças desse quebra-cabeça não encaixavam, pois as observações não coincidiam com as informações dos questionários. Foi preciso conversar com os pais e entender: por que não estavam no parque que eles mais citavam como preferência? Por que, com diferentes possibilidades econômicas nos dois bairros, ${ }^{6}$ as crianças não estavam na rua? As respostas vieram das falas dos familiares, mas antes gostaria de discorrer sobre o contexto das crianças.

Assim, início apresentando o bairro das crianças: a Vila Ipiranga e a Vila Jardim, vizinhas uma da outra e situadas na zona norte da cidade de Porto Alegre. Algumas informações que podem contribuir para a descrição desses locais são dados disponibilizados pelo IBGE, distribuídos em Unidades de

3 Foram dois bairros observados pois eram o contexto no qual as crianças circulavam pois algumas moravam em um bairro mas iam na escola em outro.

4 O mês de novembro de 2008 foi o mais chuvoso dos últimos sete anos na cidade de Porto Alegre, RS, conforme anunciavam as matérias de jornal da época.

5 Os dados identificados foram etnográficos, registrados em diário de campo e um questionário; por questões de espaço não entrarei em detalhes aqui, mas eles podem ser conferidos em Wenetz (2012).

6 Falo em bairros porque as crianças que frequentavam a escola, na sua maioria, moravam no mesmo bairro ou no bairro próximo. 
Desenvolvimento Humano (UDH) da Região Metropolitana de Porto Alegre (RMPA), que centralizam vários bairros, porém essa divisão não é definida em cada bairro. As UDHs foram demarcadas de acordo com os territórios de bairros ou microrregiões que possuem características socioeconômicas similares. Nesta pesquisa, utilizarei as unidades nomeadas "Vila Ipiranga Educandário Jardim ITU - Rua Paul Harris" e "Vila Jardim - Av. Circular", nomeando-as como Vila Ipiranga e Vila Jardim. Destaco que não utilizo essas informações com fins estatísticos, mas com a intenção de caracterizar os bairros e seu contexto urbano.

O bairro Vila Ipiranga possui diversos centros comerciais e teve sua origem no início do século 20, tendo recebido investimentos de infraestrutura a partir dos anos 1960. Dentre as melhorias realizadas, destacam-se as instalações do Hospital Conceição e do Hospital Banco de Olhos, gerando um aumento notável na circulação de pessoas, vindas do interior do estado e do centro da cidade. Encontra-se geograficamente muito próximo de shopping centers, como o Iguatemi e o Bourbon Country, e experimenta um grande desenvolvimento nos últimos anos.

A Vila Ipiranga é um bairro mais populoso do que a Vila Jardim e também com um poder aquisitivo maior. ${ }^{7}$ Atualmente, é uma das regiões que apresenta maior crescimento demográfico. ${ }^{8}$ Segundo Célia Souza (et. al, 2000), a Vila Ipiranga ${ }^{9}$ é um bairro de classe média baixa, predominantemente residencial, dispondo de pequeno comércio e serviços. Recentemente foi estabelecido ali o loteamento Jardim Europa, que ocasionou o desmatamento de uma região, a abertura e a pavimentação de ruas, a instalação de iluminação pública, a construção de vários edifícios, além de um novo parque que faz parte do empreendimento (Parque Germânia). ${ }^{10}$

7 As rendas per capita médias, no ano 2000, eram de R \$ 703,10 na Vila Ipiranga e de R \$562,40 na Vila Jardim.

8 Segundo dados do Censo do IBGE (2000), a região possui uma população de 20.951 habitantes em uma área de 220 ha. Disponível em: <www2.portoalegre.rs.gov.br/observatorio/default. php?p_bairro $=174 \&$ hist $=1 \& p$ _sistema $=\mathrm{S}>(10$ ago. 2010$)$.

9 A Vila Ipiranga tem uma população maior (17.116 habitantes) do que a da Vila Jardim (8.208 habitantes), mas possui uma área menor. Tem uma extensão de $7.695,1 \mathrm{~km}^{2}$, enquanto a Vila Jardim tem $9.911,1 \mathrm{~km}^{2}$. Desse modo, observa-se na Vila Ipiranga uma concentração populacional maior, principalmente em edifícios. A população entre sete e 14 anos nesses bairros é de 1.758 (Vila Ipiranga) e 1.060 (Vila Jardim), dos quais 98,9\% e 97,1\%, respectivamente, estão frequentando a escola.

${ }^{10}$ O Parque Alemanha, chamado pela comunidade como Germânia, fica a três quadras da escola. Foi concluído em março de 2008, possui uma área de 14,3 ha e foi construído como uma doação referente ao Loteamento Germânia, baseado na Lei Federal 766/79 e na Legislação Municipal. Possui cerca de 7,3 ha de mata nativa preservada, conforme orientação do Conselho Municipal do Meio Ambiente (Comam) e da Secretaria Municipal do Meio Ambiente (Smam). É o primeiro parque cercado na cidade. O horário de funcionamento é das $6 \mathrm{~h} 30 \mathrm{~min}$ às $20 \mathrm{~h}$. $\mathrm{O}$ 
A Vila Jardim, situada ao sul da Vila Ipiranga, até meados de século 20 foi uma região pouco habitada e tardou cerca de 10 anos para ter uma infraestrutura mais adequada, aspecto que a Vila Ipiranga já possuía. Na busca de melhores condições, os moradores iniciaram um movimento comunitário e passaram a ser parte do orçamento participativo, ${ }^{11}$ como outros bairros da cidade. O bairro é residencial, mas possui pequenos estabelecimentos comerciais na avenida do Forte e na Saturnino de Brito - avenidas principais do bairro, continuação uma da outra.

Apesar dessas diferenças, ambos os bairros possuem acesso a serviços básicos, tais como água encanada, energia elétrica e coleta do lixo, e suas populações dispõem de bens de consumo, como geladeira, televisão e telefone. Algumas casas também têm computador, mas não tanto quanto telefone. Os dois bairros têm 12 praças (muitas com excelente estrutura) e oito espaços verdes, com predominância no bairro Vila Ipiranga, o qual abriga, em uma antiga praça, a escola. Muitas crianças moravam próximas à escola. ${ }^{12}$

A escola constitui e no contexto dessa construção define uma única maneira de funcionamento e organização. Ela se distingue de outras escolas na sua especificidade, na sua rotina e cultura escolar. A escola é estadual e oferece educação infantil, ensino fundamental completo e médio regular, do primeiro ao terceiro ano, e Educação de Jovens e Adultos, funcionando nos três turnos. A direção conta com conselho escolar e setores administrativos informatizados, como secretaria, pessoal e administrativo-financeiro. Também possui setores pedagógicos (serviço de supervisão e serviço de orientação escolar), biblioteca, laboratórios de ciências, matemática e informática, sala

parque apresenta um prédio administrativo, quatro quadras poliesportivas, duas quadras de tênis, pistas de caminhada e corrida, chafariz, três canchas de bocha, um lago, sanitários e churrasqueiras. Além disso, dispõe de equipamentos ou playground para recreação infantil distribuídos em diferentes pontos. Também tem um serviço de segurança, providenciado pela construtora do novo bairro. A comunidade vai usufruindo desse espaço à medida que construções, iluminação e segurança são implantadas.

${ }^{11}$ Orçamento Participativo é um mecanismo governamental que permite aos cidadãos influenciar ou decidir sobre os orçamentos públicos. Através desses processos de participação, decide-se através de discussões (ou assembleias) públicas sobre os orçamentos e em quais locais serão realizados os investimentos.

12 As crianças observadas são da primeira à quarta série do ensino fundamental, meninos e meninas. As idades são homogêneas mas tem algumas crianças repetentes chegando aos 14 anos. Elas não trabalham e realizam algumas ajudas ou tarefas domésticas em casa, estudam e assistem TV, telefone e internet em casa. Na sua maioria não realizam atividades físicas fora da escola. Algumas delas participam dos dois projetos escolares que funcionam dentro do espaço escolar: as danças gaúchas (meninos e meninas) e o futebol (meninos). No geral, as crianças moram em casas com pátio e têm um cuidador adulto, portanto, elas não ficam responsáveis pelos irmãos. Tem uma minoria que fica sozinha um turno do dia, e elas são supervisionadas pelo telefone pelas mães. 
de audiovisual, círculo de pais e mestres, banda marcial e grêmio estudantil, do qual participam jovens do ensino médio.

O corpo docente é composto de 80 professores, a equipe de funcionários tem 14 pessoas, e o corpo discente possui em torno de 1.300 alunos. Além do grupo docente, um casal trabalha e mora no terreno da escola há aproximadamente seis anos. Essa família cuida da portaria, da segurança da instituição durante a noite e, geralmente, resolve alguma dificuldade em relação a mantimentos. O terreno da escola é muito heterogêneo, tanto em níveis quanto no tipo de solo, possuindo declives e muitas árvores. Estas se encontram no entorno da escola. Mas vejamos porque falo da etnografia dos espaços vazios.

\section{Etnografia dos espaços vazios}

É possível estabelecer relações entre a cidade e as pessoas que nela habitam? A maneira como os sujeitos vivem e constroem suas cidades e o modo que vivenciam essas experiências têm sido objeto de estudos de várias áreas, entre elas a arquitetura, o planejamento urbano, a geografia e - por que não? - a própria antropologia.

A antropologia - ou, mais especificamente, a antropologia urbana - tem pesquisado esses temas. Magnani (2003, p. 2) chama nossa atenção de que a antropologia urbana poderia ser entendida como um "desenvolvimento tardio da própria antropologia”, pois apresenta alguns dos mesmos antecedentes sobretudo aqueles direcionados aos povos primitivos. Assim, elas têm sido atravessadas por similares transformações, nas quais o desafio em comum consiste em "tentar reproduzir, principalmente no cenário das grandes metrópoles, aquelas condições tidas como clássicas na pesquisa antropológica: a dimensão da aldeia, da comunidade, do pequeno grupo". Ou seja, como a antropologia urbana - que tem como método principal a etnografia - consegue operar no contexto urbano sem cair no que o autor denomina "tentação da aldeia", pela qual o pesquisador buscaria, no contexto heterogêneo, amplo e diversificado da cidade, aqueles grupos pequenos em contextos limitados (aldeia).

A etnografia sofreu transformações, pois a tradição etnográfica caracterizou-se, segundo Winkin (1998), por três momentos revolucionários. O primeiro deles começou transformando aquilo que poderíamos chamar de 'estranho em familiar', com a observação participante de grupos culturais diferentes e alheios ao pesquisador, como diferentes sociedades de 'nativos' de ilhas pequenas que se encontravam longe da entendida civilização. Num segundo momento, os antropólogos passaram a questionar-se sobre aquilo 
que se conforma na sua própria sociedade, observando diferentes grupos dentro das cidades, como minorias sociais ou alguns grupos específicos de fácil diferenciação no contexto da cidade etc. Finalmente, num terceiro momento, percebe-se que não é preciso trabalhar só com gangues e outros grupos minoritários. $\mathrm{O}$ autor entende que não é mais necessário observar a cidade e problematizar aqueles grupos entendidos a priori como perigosos ou complicados. Desse modo, podem-se utilizar lugares simples, cotidianos e comuns, porque eles "vão revelar-se à análise terrivelmente complexos" (ibid., p. 130). Nessa direção, perguntei-me: como esses sujeitos vivenciam a cidade e fazem dela um espaço próprio? Quais desses espaços são destinados às crianças? Que espaços urbanos elas ocupam? Que práticas realizam?

Nas cidades e nos parques urbanos, alguns elementos podem se fazer presentes, como a violência urbana, as políticas públicas, as práticas de lazer da comunidade (cf. Fraga et al., 2009), a estrutura das praças ${ }^{13}$ etc. Embora tais temáticas não sejam objetivo deste artigo, elas fazem parte do contexto cultural. Assim, ao pretender problematizar como crianças constroem suas vivências coletivas em diferentes espaços, de maneira indireta os parques refletem características que atravessam ditas temáticas mais abrangentes.

A etnografia tem como finalidade mapear os significados e as construções presentes nas relações dos sujeitos e contribui, ainda, para compreender a importância da relação subjetiva entre o pesquisador e o contexto a ser pesquisado em sua particularidade. Mas, ao longo do caminho pelo qual a pesquisa foi se encaminhando, deparei-me com um problema não previsto: a ausência das crianças no parque e nas ruas. Como realizar, no contexto da cidade, uma etnografia sem os sujeitos? Particularmente, como realizar uma etnografia dos espaços vazios? Cabe destacar que não estou aqui negando a importância do espaço, já que ele não constitui meramente um cenário onde as 'outras' coisas acontecem, desarticuladas do contexto. Afinal, é também através da arquitetura que se configuram significados de diferentes maneiras e formas. ${ }^{14}$ Trarei agora algumas reflexões dos pais sobre por que as praças estavam vazias.

\section{Entre anônimos e conhecidos: "mas tu não imaginava?"15}

Ao conversar com alguns dos familiares das crianças sobre o tema da pesquisa ou ao dizer a eles que não tinha encontrado crianças em ruas e praças, Andréia, uma das mães que frequentava a escola, olhou para mim e com muita

13 Em relação a esse assunto, ver trabalhos de Simone Rechia $(2005,2006)$.

$14 \mathrm{O}$ debate sobre os espaços foi aprofundado na tese (Wenetz, 2012).

15 Fala de uma mãe em entrevista no dia 28/11/2009. 
naturalidade me questionou: "Mas tu não imaginava?" O tom com o qual ela me questionou fez-me sentir ingênua. Como se eu estivesse esperando uma condição que, para ela, mãe de duas meninas, era impossível aceitar: deixar as crianças brincar na rua!

Isso me obrigou a pensar no motivo de a mãe considerar essa impossibilidade. Comecei, então, durante as entrevistas com as mães, a indagar um pouco mais sobre essa temática: de que tinham receio ou preocupação? Era possível ou não deixar seus filhos e filhas brincarem na rua? Carine, mãe da Diana, respondeu-me:

Carine: A gente costuma, aqui no parque, a gente gostava muito final de semana, mas ultimamente devido à violência a gente está evitando [...].

Pesquisadora: Nesse bairro dá para deixar as crianças brincarem na rua?

Carine: Aqui, antigamente dava, hoje não dá mais. Hoje se tu for aqui nesse parque [Germânia], sozinha não tem como, em lugar nenhum. [...] As minhas preocupações assim, são, é, os adultos, esse negócio de droga, e violência, e atentado ao pudor, isso são coisas que me preocupam muito [...] (Entrevista mãe, Carine, 17/11/2009).

De todos os familiares entrevistados, nenhum apresentou alguma explicação que fosse diferente de uma sensação de insegurança ou de um movimento de precaução no cuidado da criança. Também ninguém especificou por que não ia com tanta frequência ao Parque Germânia. Uma mãe afirmou que atualmente se vive num período um pouco mais violento que antigamente. Outra mãe relatou uma experiência no Parque Germânia, a qual cito integralmente, embora seja um pouco extensa:

[...] e ela estava ali brincando [com sua filha] e eu vi uma movimentação diferente. Não vou dizer que eu vi, eu senti, na verdade. Eu disse, 'Diana vamos embora, não, vamos Diana, tá muito cheio isso aqui, é muita gente'. Porque a gente mora aqui já faz vinte e poucos anos, e eu conheço as caras, mesmo que eu não saiba o nome, e eu não sei, eu conheço de ver, de passar. $\mathrm{O}$ bairro é muito próximo, então a gente vê as pessoas. E eu disse: 'Diana, tem gente que não é daqui aqui'. E tu via pelas vestimentas, pelas atitudes. 'E deu vamos embora, e vamos embora'. Quando chegamos aqui no topo da lomba, eu olhei lá para baixo, era polícia entrando de um lado, era cavaleiro entrando do outro, era moto... A polícia invadiu o parque, e deu aquela correria, e eu mostrei Diana, 'olha lá'. Depois eu fiquei sabendo que eram gangues da Vila Jardim com a da Bom Jesus, que tinham marcado um encontro pra fazer um 
pega, para fazer um arrastão, e enfim. Depois eu fui saber de tudo isso, depois eu descobri que existem policiais à paisana que ficam no meio do público. Depois que eu conheço um guarda municipal que a esposa dele é cliente da minha mãe, e aí eu ali no parque um final de semana - é, nós estávamos jogando vôlei, eu e ela-, aí encontrei ele, daí ele veio e me contou que final de semana existem 20 policiais à paisana dentro do parque. Eles ficam assim dentro do parque, como nós duas aqui, conversando, mas eles têm um ponto no ouvido, e eles se infiltram no meio da gurizada, no meio das ganguezinhas ali, que eles veem que não são dali, e ficam. Daí eu disse, 'pois é, aquele dia...', daí ele disse 'aquele dia foi marcado pelo Orkut, o encontro das duas gangues, e a polícia teve acesso a isso. E quando eles viram que a coisa ia fechar, aí eles invadiram. Os policiais já estavam todos perto.' Aí eu fiquei um pouco mais tranquila, aí depois que eu fiquei sabendo disso eu consegui identificar alguns policiais ali, né. Eles estão à paisana, são pessoas normais, tão ali tomando chimarrão, lendo jornal. Realmente tu não percebe, mas eles ficam ali tomando chimarrão, ficam conversando, ficam caminhando, mas são policiais da Brigada Militar, então eu já fiquei mais tranquila [...]. (Entrevista mãe, Carine, 10/12/2009).

Nesse relato, podemos observar como aconteceram alguns fatos problemáticos, embora tenha sido a única fala sobre isso. Eu não estava presente no dia e no horário desse episódio, no entanto, revisando meus diários de campo, tinha percebido um aparente esvaziamento de pessoas no parque durante os finais de semana. Apesar de o relato de Carine indicar a insegurança no parque, este tem um serviço de segurança privada, como já destaquei. Desse modo, o cuidado, o cercamento, a iluminação, a limpeza e, inclusive, a circulação de policiais à paisana são elementos de um investimento particular que não existe, em geral, nos outros parques e praças da cidade.

Nesse caso específico, Carine fala-nos de um acontecimento vivido para justificar seus medos e preocupações em deixar sua filha brincar na rua e nos parques. A maioria dos familiares tem medo de que alguma coisa possa vir a acontecer e justifica esse medo com uma vivência ou violência em particular. Há uma sensação de insegurança que configura tanto a escolha dos lugares para o lazer das famílias quanto a frequência dessas visitas. Carine continuou levando a filha ao parque, mas com menos frequência, e nunca permitiu que a criança fosse sozinha ou apenas com os amigos.

Nesta pesquisa, os bairros observados demonstraram diferenças. A Vila Ipiranga possui inúmeras praças vazias. No caso da Vila Jardim, não havia praças, mas muitos becos - um deles até com uma pequena quadra de futebol pintada - que também estavam sempre vazios. Sobre os motivos pelos quais as 
crianças não brincavam na rua, uma das mães entrevistadas diz: "Não, aqui não dá! Nessa rua é via de tráfico, eles passam por aqui, tem tiroteio" (Entrevista com mãe, 24/10/2009). A seguir, será examinado com mais detalhes o que os familiares têm a dizer sobre os motivos da ocupação, ou não, desses espaços extraescolares.

\section{Por que há espaços vazios? Vestígios de medo no ar}

Um dia, eu estava lendo o jornal Correio do Povo e havia uma manchete que chamou minha atenção: "Porto Alegre está com medo". O artigo continuava: "pesquisa do Instituto Methodus mostra que 55\% da população diz que não se sente segura na rua ou em casa" (Correio do Povo, 7 dez. 2010 , p. 16.). A imagem que estava abaixo da chamada tinha um conjunto de policiais vestindo seus uniformes e em fileiras. Na notícia, o chefe de polícia dizia acreditar que os números da pesquisa eram normais, pois "a sensação de insegurança irá ser minimizada a partir do momento em que a população sente uma presença maior do estado nas ruas". No entanto justificava essa afirmação, destacando que, numa cidade grande como Porto Alegre, "espalhada, a presença do policiamento se dissolve, não dando a perceber o aumento do efetivo, ao contrário do que ocorre em uma cidade pequena".

Ao ler essa reportagem, fiquei perguntando-me: será que é suficiente justificar essa sensação de insegurança só porque a cidade é grande? Será que é necessário um policiamento em cada rua para nos sentirmos seguros? Será que as crianças e seus familiares se sentem seguros para utilizar espaços públicos como as praças? Utilizarei essa relação, articulada com as respostas dos familiares, para tentar responder: onde as crianças estavam? Por que não estavam na rua?

Das falas dos familiares, algumas características repetiam-se: medo; medo ao estranho; confiança; não ter parceiros para as brincadeiras; e falta de espaços para brincar na cidade. Assim, em relação ao medo, os familiares falaram:

Pesquisadora: Sim, e tu andava mais na rua assim para brincar?

Margarete: Por tudo. Nosso pátio tinha até mato. A gente ia pelos matos, tudo assim, brincar. Na época ainda, eles estavam construindo os prédios do Jardim Ipiranga. A gente brincava por vários lugares. Não tinha perigo, naquele tempo não se tinha tanto medo assim como hoje. Jamais deixaria a Fátima [sua filha] ir sozinha, mesmo sabendo que vai várias pessoas para o mesmo lugar, que é perto né. Pesquisadora: É perto, é? 
Margarete: É perto. É só atravessar a praça. Vai reto aqui, atravessa a praça e desce a rua. E ela sabe. Mas eu tenho medo. Tenho medo, porque sei lá. Sei lá, não sei. Naquele tempo nós andava, brincava, vinha com colegas sozinha, nunca aconteceu nada, mas hoje em dia tenho medo, não deixo. Ela, com oito anos que vai fazer, nunca veio sozinha [...] (Entrevista com uma mãe, 1\%/12/2009).

Outros pais expressavam a mesma preocupação, quando o assunto era a rua e as suas possibilidades de ser um lugar para brincar. Eles exprimiram a sua insegurança em relação à rua da seguinte forma: "Eu tenho medo" (Jussara - uma mãe -, 15/12/2009); "A violência" (uma mãe, 1\%/12/2009); "Pedofilia" (um pai, 1\%12/2009). O medo de que os familiares falam não parece ter alguma referência específica. Ora é o perigo que não consegue definir uma só causa, ora é a violência, ora é a pedofilia, ou simplesmente o medo que está presente, porém não se sabe definir de quê. Bauman (2008, p. 8) entende que o medo "[...] é mais assustador quando difuso, disperso, indistinto, desvinculado desancorado, flutuante, sem endereço nem motivo claro".

Nessas poucas palavras, o autor traduz, em certa medida, o que os pais hoje vivenciam na contemporaneidade para a educação e a sociabilidade de seus filhos. Continuando com as ideias de Bauman, o medo pode ter duas características. Por um lado, o temos num sentido direto; ao vivenciarmos um acontecimento que nos amedronta, podemos continuar sentindo medo com o passar do tempo, ao estarmos frente a uma situação que nos lembre o acontecido. Por outro lado, temos um "medo derivado": podemos novamente sentir-nos temerosos ante uma situação aparentemente relacionada a uma experiência, apesar de não ser uma ameaça presente. Isso pode ser definido como "o sentimento de ser suscetível ao perigo; uma sensação de insegurança” (ibid., p. 9). Essa sensação de insegurança não precisa de causas reais para se fazer presente.

Os medos podem ser definidos em três grandes grupos. O primeiro é aquele que ameaça o próprio corpo e as propriedades que as pessoas têm. $\mathrm{O}$ segundo faz referência à "durabilidade da ordem social e à confiabilidade da qual depende a segurança do sustento", seja do sujeito, seja do grupo familiar, como a renda ou o emprego, inclusive nos casos de invalidez ou velhice. $\mathrm{O}$ terceiro grupo constitui aqueles medos que ameaçam a pessoa em relação ao mundo, como a "hierarquia social, a identidade (de classe, de gênero, étnica, religiosa), que conformam em aspectos mais gerais as situações como degradação ou exclusão social” (Bauman, 2008, p. 10).

No caso de alguns familiares participantes desta pesquisa, uma minoria faz referência a uma vivência em particular, como podemos observar no trecho a seguir: 
Avó: Eles ficam assistindo TV e aí eles jogam um pouco de Play, mas na rua, assim, eu não deixo ir, a não ser ali onde tu entrou naquele corredorzinho ali né, aquela partezinha, ali eles brincam à vontade. Aqui dentro também, lá na rua não.

Pesquisadora: Não?

Avó: Não, lá na rua nós não deixamos ir.

Pesquisadora: E por que não? Quais seriam as preocupações que a senhora tem?

Avó: Porque é perigoso né, quando a gente menos espera dá um tiroteio aí, e as crianças tão na rua. Daí a gente sai daqui e correndo lá para tirar da rua. Aí eles são crianças e não conhecem o perigo. Meu filho faleceu ali na esquina. (Entrevista com Avó, 31/10/2009).

Nesse relato, podemos ver o primeiro tipo de medo que anunciei. Ainda é possível perceber como a experiência de ter perdido um familiar modificou toda a relação do grupo familiar com o espaço e com a rua. A família mora num beco onde não é possível transitar de carro, pois há várias escadas que constituem o espaço ao qual a avó se refere como rua. O corredor de que ela fala é o que se desprende desse beco comum a várias casas, que não deve ter mais de dois metros de largura por três metros comprimento. As crianças brincam nesse espaço ou na escola.

Cabe destacar que esse foi o único exemplo em que os familiares tinham um medo em relação à rua, com base em algum fato "real" que lhes tenha ocorrido. Na maioria dos casos, era um medo ou uma sensação de insegurança que podia fazer referência a diversos aspectos, com dificuldade de identificar só algum aspecto ou momento em particular. Bauman (2008, p. 11) explica que

[...] o que mais amedronta é a ubiquidade dos medos, eles podem vazar em qualquer canto ou fresta de nossos lares e de nosso planeta. Das ruas escuras ou das telas luminosas dos televisores. De nossos quartos e de nossas cozinhas. De nossos locais de trabalho e do metrô que tomamos para ir e voltar. De pessoas que encontramos e de pessoas que não conseguimos perceber [...].

De onde vem, então, essa necessidade de segurança? Bauman utilizando as ideias de Castel, enuncia que nosso sentimento de insegurança deriva não da falta de proteção, mas de "um tipo de universo social que, como o nosso, 'foi organizado em torno da infindável busca de proteção e da frenética busca de segurança"” (ibid., p. 169). Vivemos, desse modo, em uma "obsessão com segurança", colocando sempre, ante nós mesmos, objetivos cada vez mais inatingíveis. 
Os medos parecem ser configurados de diferentes modos nas cidades. No caso desta pesquisa, os familiares das crianças possuíam um medo que muitas vezes estava direcionado ao espaço distante, como a praça ou as pessoas que não conheciam. Bauman (2009, p. 75) contribui para o entendimento desse ponto:

Quanto mais o espaço e a distância se reduzem, maior é a importância que sua gente lhe atribui: quanto mais é depreciado o espaço, menos protetora é a distância, e mais obsessivamente as pessoas traçam e deslocam fronteiras. É sobretudo nas cidades que se observa essa furiosa atividade de traçar e deslocar fronteiras entre as pessoas.

Ao buscarmos as diferenças, demarcamos nossas fronteiras e alimentamos nossos medos, como podemos observar nas falas a seguir:

É. Mais pelo lugar, né. A gente sempre chega e senta lá [Bairro Jardim Ipiranga], pelas pessoas que convive, não pelos guris que estão jogando, mas sim pelas pessoas [...]. (Entrevista com mãe, Adelaide, 4/12/2009).

Não, eu tenho medo da rua e tenho medo também dos outros que participam lá, porque eu já vi já, tem outros grupinhos. (Entrevista com mãe, Luciana, 1/12/2009).

Pesquisadora: E elas descem sozinhas ou tu preferes descer junto? [aqui faço referência a sair do prédio para brincar na praça].

Leonor: Não, só comigo ou com alguém responsável, nunca sozinhas.

Pesquisadora: Quais seriam tuas preocupações?

Leonor: De roubarem elas [risos], de roubarem, de acontecer algum mal... Nunca deixo sair sozinha, não deixo fazer nada assim, não deixo dormir na casa das amigas, sou muito... Tenho medo, que tá muito perigoso hoje em dia. (Entrevista com mãe, Leonor, 28/11/2009).

Nos trechos destacados, podemos mapear, de maneira geral, um medo ao outro, ao estranho, mais do que, por exemplo, as crianças se machucarem de algum modo ao não ter um adulto por perto. Os medos também podem ser observados em falas anteriores, quando os pais dizem que se preocupam com pedofilia, roubos ou violência de outros grupos.

Bauman (2009, p. 37) entende que as pessoas com medo do desconhecido buscam alguma forma de conforto. Assim, "as ânsias acumuladas tendem a se descarregar sobre aquela categoria de 'forasteiros' escolhidos para encarnar a 'estrangeiridade', a não familiaridade, a opacidade do ambiente em que vive e 
a indeterminação dos perigos e das ameaças". O estranho é definido pelo autor como aquele sujeito que supomos quais são as suas intenções e o que podemos esperar dele, apesar de nunca termos certeza disso. Desse modo, sua presença e convivência nos desconcertam, tornando absurda a tarefa de "prever os efeitos das ações e suas chances do sucesso ou insucesso" (ibid., p. 38).

O estranho rompe com a organização da vida diária; ele "não partilha as suposições locais - e, desse modo, torna-se essencialmente o homem que deve colocar em questão quase tudo o que parece ser inquestionável para os membros do grupo abordado" (ibid., p. 19). Conviver com os estranhos implica "viver na sua indesejada e incômoda proximidade, é uma condição que os habitantes da cidade acham difícil, talvez impossível de escapar [...] mas a forma pela qual os moradores das cidades se ocupam do atendimento de suas demandas é uma questão de escolha" (id., 2007, p. 92). ${ }^{16}$

Os medos parecem ser configurados de diferentes modos nas cidades. No caso desta pesquisa, os familiares das crianças colocam que para poder ficar na rua, as crianças devem ter com quem partilhar suas brincadeiras.

Eu não sei nem como deixar ele brincar na rua. Eu acho que nem ele conseguiria, porque é uma coisa assim, que não tem... Primeiro porque não tem nada pra fazer na rua, na calçada, ali, não tem criança. Os amigos dele da escola que são nossos vizinhos de rua, e também não vão para rua. Sabe, não tem nenhum amigo dele assim, que a gente olha na janela e está na calçada brincando, também não vão. É que a mãe deles também não deixa. (Entrevista mãe, Valéria, $3 / 12 / 2009$ ).

Além do aspecto do medo, foi possível identificar uma nova configuração da criança. Assim, durante a realização das entrevistas não foi difícil confirmar que crianças na idade pesquisada, além do turno na escola, passam pelo menos um turno do dia sozinhas em casa (nem que seja temporariamente). Algumas delas tomam café da manhã, banho e almoço até vão à escola sem a presença de um adulto em casa. Mas isso é entendido pelos pais como uma coisa necessária, embora a criança esteja vigiada no prédio, através dos serviços de segurança (ou através dos telefonemas das mães) ou da instrução de não poder descer do apartamento.

Não estou dizendo, com isso, que os familiares vivem essas situações de maneira negligente e leviana, sem medo ou preocupação. Muitas das mães

${ }^{16} \mathrm{O}$ autor faz referência ao estranho no sentido do estrangeiro, cuja imigração configura a cidade e os diferentes mecanismos de inclusão e exclusão, inclusive econômicos. Contudo não aprofundarei esse aspecto. 
entrevistadas ainda estavam procurando uma saída para essas situações. Só quero destacar o quanto temos em nossa compreensão de que o perigoso só se encontra fora de casa, e não dentro dela. Calaf (2007, p. 46) estudou crianças que moravam na rua, em Brasília, e indagou se elas eram crianças ou não. Uma respondeu:

[...] aí depende porque criança pode ser todo mundo, o compadre ali pode ser criança. Agora, são crianças diferentes [...]. Questão de saber se virar mesmo, de saber de coisa que os filhinhos da mamãe nem imagina, nem sonha que existe, e que muito marmanjo também não sabe não $[\ldots]$.

Nessa citação podemos observar como a noção de ser criança pode ter outros significados na rua, enquanto que para os pais das crianças da escola a sensação de insegurança atravessa o cotidiano. Embora essas sensações de insegurança persigam os pais, os relatos foram em um tom nostálgico - como dizer "todo tempo passado foi melhor" - e não observando as novas formas de sociabilidade que a criança adquire.

Assim, por um lado, temos esses entendimentos de que as crianças estão "crianças aprisionadas", como fala a mãe; temos a criança "limitada" quanto aos lugares e atividades que ela pode frequentar; e temos, ainda, crianças "responsáveis", que se viram, na maior parte do tempo, sozinhas. Por outro lado, há outra configuração de sociabilidade da criança, na qual ela consegue dispor, praticamente sozinha, em que parte do prédio fica e tem uma relativa "autonomia" para decidir o que vai fazer. No caso de ficar sozinha em casa, também decide o que fará durante esse turno, seja uma atividade física, virtual, de higiene pessoal, realizar tarefas ou simplesmente olhar televisão.

Não é estranho que hoje crianças decidam que atividades realizarão, em quais horários e definam ainda o lugar onde vai ser feito - fazendo com que as famílias tenham de se organizar com base naquelas demandas, para permitir que a criança participe. Decidem se ficam ou não na escola a realizar outras atividades, fazem amizades em curtos períodos de tempo e, dependendo dos diferentes espaços nos quais brincam, criam diferentes grupos de amizade etc. Isso, sem dúvida, constitui diferentes formas de sociabilidade em que a criança vivencia novas e diversas formas de conviver com os pares e sua comunidade.

\section{Conclusão}

Neste artigo, tentei identificar o contexto da cidade no qual as crianças se encontram inseridas para visualizar quais são as relações de sociabilidade que 
elas tinham. Temáticas como planejamento urbano, sensação de insegurança, espaços de lazer urbanos (praças, ruas ou outros) tornaram-se um grande guarda-chuva que configura as características das vivências coletivas das crianças e as possibilidades desses espaços e brincadeiras. Nesse contexto, foi possível identificar a polissemia da rua, mas na qual a ausência das crianças permite observar que familiares se refiram a ela como um espaço de 'perigos', por estar ligado aos espaços abertos, difusos.

O bairro, com suas características gerais, sua movimentação, seus aspectos geográficos, seus espaços disponíveis, sua articulação com a cidade, vai formar, de alguma maneira, as vivências coletivas das crianças. Desse modo, as praças são representadas no senso comum e acadêmico como um espaço aberto, disponível e adequado para as crianças brincarem, mas, conforme as observações realizadas, as praças nas grandes cidades vêm se tornando, crescentemente, espaços vazios. Nesse contexto urbano e através das identificações desses diferentes espaços no bairro onde a escola se encontra inserida e no qual as crianças circulam, foi possível identificar o quanto a cidade não lhes oferece espaços de sociabilidade (seguros) e como seus pais ou responsáveis, por diferentes motivos, têm medo do "estranho" e da rua e não têm confiança nesses espaços.

\section{Referências}

BAUMAN, Zygmunt. Medo líquido. Rio de Janeiro: Jorge Zahar, 2008. . Confiança e medo na cidade. Rio de Janeiro: Jorge Zahar, 2009.

CALAF, Priscila Pinto. Criança que faz criança: (des)construindo infância e sexualidade com meninos e meninas de rua. 2007. Dissertação (Mestrado em Antropologia) Programa de Pós-Graduação em Antropologia Social, Instituto de Ciências Sociais, Universidade de Brasília, Brasília, 2007.

FRAGA, Alex Branco et al. (Orgs.). Políticas de lazer e saúde em espaços urbanos. Porto Alegre: Gênese, 2009. (Série Esporte, Lazer e Saúde).

JACOBS, Jane. Morte e vida de grandes cidades. São Paulo: Martins Fontes, 2009. (Coleção Mundo de Arte).

MAGNANI, José Guilherme C. A antropologia urbana e os desafios da metrópole. Tempo Social, São Paulo, v. 15, n. 1, p. 81-95, abr. 2003. <www.scielo.br/pdf/ts/v15n1/ v15n1a05.pdf>. (10 out. 2010).

PORTO Alegre está com medo. Correio do Povo, Porto Alegre, p. 16, 7 dez. 2010.

RECHIA, Simone. Espaço e planejamento urbano na sociedade contemporânea: políticas públicas e a busca por uma marca identitária na cidade de Curitiba. Movimento, Porto Alegre, v. 11, n. 3, p. 45-65, 2005.

. O jogo do espaço e o espaço do jogo em escolas da cidade de Curitiba. Revista Brasileira de Ciencias do Esporte, Campinas, v. 27, n. 2, p. 91-104, jan. 2006. 
SARMENTO, Manuel Jacinto. Gerações e alteridade: interrogações a partir da sociologia da infância. Educação Social, Campinas, v. 26, n. 21, p. 361-378, maio-ago. 2005.

SOUZA, Celia Ferraz; MULLER, Doris Maria. Porto Alegre e sua evolução urbana. Porto Alegre: Editora da Ufrgs, 1997.

WENETZ, Ileana. Presentes na escola e ausentes na rua: brincadeiras de crianças marcadas pelo gênero e pela sexualidade. Tese (Doutorado em Ciências do Movimento Humano) - Programa de Pós-Graduação em Ciências do Movimento Humano, Escola de Educação Física, Universidade Federal do Rio Grande do Sul, Porto Alegre, 2012.

WINKIN, Yves. A nova comunicação: da teoria ao trabalho de campo. Campinas: Papirus Editora, 1998.

\section{Autora correspondente:}

Ileana Wenetz

Rua Antônio Francisco da Silveira, 529, apto. 1 - Pantanal

88040-160 Florianópolis, SC, Brasil

Recebido em: 5 jul. 2013

Aprovado em: 9 out. 2013 